\title{
Recommendations for healthcare providers preparing to work in the Middle East: A Campinha-Bacote cultural competence model approach
}

\author{
Jessie M. Johnson*, Cathy D. MacDonald, Linda Oliver \\ University of Calgary in Qatar, Doha, Qatar
}

Received: June 1, 2016

DOI: $10.5430 /$ jnep.v7n2p25

\author{
Accepted: September 6, $2016 \quad$ Online Published: September 18, 2016 \\ URL: http://dx.doi.org/10.5430/jnep.v7n2p25
}

\begin{abstract}
Healthcare providers (HCPs) seeking professional and personal development via an international placement may be enticed to choose the Middle East. With a unique setting and lifestyle rich in culture, tradition, history and religion, the Middle East also offers financial benefits that are more difficult to achieve in one's own country of origin. Making a successful transition to another culture requires time and preparation to mitigate culture shock. The authors highlight some key recommendations to aid healthcare providers in transitioning to work in the Middle East. These recommendations are based on Campinha-Bacote's (2002) cultural competence model, with the core tenets of cultural awareness, cultural knowledge, cultural skill, cultural encounter and cultural desire. Guidelines for transitioning to work in the Middle East are applicable to all healthcare providers and to other settings.
\end{abstract}

Key Words: Healthcare providers, Cultural competence, Middle East, Culture shock

\section{INTRODUCTION}

Choosing to work in any new cultural context can be challenging for anyone. This occurs in spite of perceived benefits such as those associated with professional opportunity, monetary gain or knowledge acquisition. Although healthcare providers (HCPs) may choose the Middle East (ME) for personal or professional opportunities, the transition may not be easy. Whether working in a hospital, university or another organization there are many variables influencing adaption. Geography, climate, traditions, religion, cultural mores and practices are some of those variables. Organizational culture and the broader societal culture will be different. According to Schumacher and Melais ${ }^{[1]}$ transitioning "can produce profound alterations in the lives of individuals and their signifi- cant others and have important implications for well-being and health" (p. 442). Achieving a successful transition requires concentrated time and consideration to acclimatize to the culture.

To achieve the necessary competencies to work overseas, HCPs must become well versed in the area of cultural competence $^{[2,3]}$ and acquire knowledge about cultural norms and religious expectations. According to the World Health Organizations Global Health Workforce Alliance ${ }^{[4]}$ it is imperative HCPs position themselves mentally and proficiently to achieve cultural competence prior to being employed in a Middle Eastern country. By extension, achieving cultural competence should be part of professional preparation for working in any culture different from one's own. While some

*Correspondence: Jessie M. Johnson; Email: jessie. johnson1@ucalgary.ca; Address: University of Calgary in Qatar, Doha, Qatar. 
literature indicates there has been an abundance of healthcare providers who have worked overseas, ${ }^{[5-7]}$ it has been noted that many HCPs experienced culture shock when not adequately prepared for this role. The purpose of this paper is to provide reccomendations to assist HCPs in the prevention or minimizing of cultural shock and promote successful transition to international work. Although there are many different cultures to draw on, the authors are using the ME as an example. Although there may be many models or frameworks to assist in the development of cultural competence, the authors recommend using a cultural competence framework. The framework chosen for this paper is the cultural competence model from the work of Campinha-Bacote. ${ }^{[3]}$ This five stage model was chosen because it describes processes that HCPs could employ to become culturally competent in the delivery of healthcare. The five stages are cultural awareness, cultural knowledge, cultural skill, cultural encounter and cultural desire.

\section{BACKGROUND}

Though referred to herein as the ME, it is acknowledged that, within this geographical region, there will be many cultural variations and many subcultures. Nevertheless, there are also commonalities. The ME is compromised of a number of countries; some of which are the richest countries in the world. These countries offer international HCPs lucrative salaries, high end housing and some tax exemptions in return for educated HCPs skilled in diverse specializations. Muslim countries such as Saudi Arabia, the United Arab Emerites, Qatar and Oman employ internationally educated HCPs and educators, as well as other foreign educated professionals and non professionals. Collectively, these expatriates (expat) workers comprise a significantly large portion of the host country's population. Logically, expatriates might be expected to contribute to anticipated and unanticipated cultural change. As with most developed nations, some of the Middle Eastern coutries have national healthcare that is becoming modeled on Western and European philosophies of medicine. ${ }^{[8,9]}$ In a broad sense, foreign educated HCPs working in these countries can expect the challenge of transitioning to multiple cultures.

Culture is often considered to include the knowledge, beliefs, behaviours, language, and rituals that characterize a group of people. ${ }^{[10]}$ Culture can encompass people in a wide geographical area (e.g. citizens of a country), or, as subcultures, people in a small, cohesive group (e.g. members of a hockey club). ${ }^{[11]}$ Working primarily in a Muslim culture can present challenges for HCPs who are unaware of cultural and religious practices, beliefs and expectations. One example is how countries will differ as to how the Qu'an is interpreted, such as with practices associated with the roles and responsibilities of men and women. It is recommended that international HCPs aware of roles, values, beliefs and expectations. Successful adaptation to a new culture requires one to unpack one's own beliefs, values and cultural biases and spend some valuable time reflecting on why they want to work in a culture vastly different from their own. This selfreflection will better prepare HCPs to become well versed and to situate themselves within that particular culture.

\section{Application of CAMpinha-Bacote CULTURAL COMPETENCE MODEL FOR HEALTHCARE PROVIDERS}

International HCPs working in the ME may experience culture shock if not adequately prepared to work in a culture that is very different from their own. According to Oberg, "culture shock can be defined as the psychological disorientation experienced by people who suddenly enter radically different cultural environments to live and work" ${ }^{[11]}$ as cited in. ${ }^{[12]}$ Although this definition was coined to embody the elements related to people living and working elsewhere other than their own geographical location, we contend that it is relevant as well to international HCPs transitioning to work in the ME, especially for their first time. This model of cultural competence in health care delivery is one model that HCPs can use as a framework for developing and implementing culturally responsive health care services ${ }^{[3]}$ (p181). To assist with cultural transitioning Campinha-Bacota's ${ }^{[13]}$ cultural competence model, with the core tenets of cultural awareness, cultural knowledge, cultural skill, cultural encounter and cultural desire are recommended.

\section{Cultural awareness}

According to Campinha-Bacote, ${ }^{[3]}$ cultural awareness "is the self-examination and in-depth exploration of one's own cultural and professional background" (p.182). This is the process of self-reflection alluded to earlier in the paper. Anyone who intends to work overseas should be aware of the diversity with which people live, be open minded, and embrace cultural differences. In Western society many hold the belief that the ways we think and teach are the norm. However, once embedded in a culture unlike our own, it is difficult to imagine that things we see are not abnormal for those that live within that culture. ${ }^{[14]}$ According to AI Yateem and AIYateem $^{[15]}$ HCPs need to be aware of the different cultural meanings patients and nursing students ascribe to certain behaviors; yet this has not always been well received. Being culturally aware is the epitome of becoming culturally competent, which helps to recognize discrimination and avoid stereotyping. ${ }^{[16]}$ Cultural competence embodies the appli- 
cation of knowledge, skills, attitudes or personal attributes required to maximize respectful relationships with diverse populations of clients and co-workers. ${ }^{[17]}$ In order to avoid biases, knowledge about the particular culture one is working in is essential.

All HCPs need to be educated in cultural awareness to be culturally competent. Cultural awareness involves being aware of ones own beliefs both personally and professionally, while positioning oneself to being open to others beliefs and awareness. ${ }^{[18]}$ Cultural awareness involves self-reflection and self-examination of personal cultural beliefs, values and and assumptions. ${ }^{[3]}$ The authors of this paper support the importance of cultural awareness to foster the building of relationships to provide holistic care.

\section{Cultural knowledge}

"Cultural knowledge is the proces of seeking and obtaining a sound educational foundation about diverse cultural and ethnic groups"[3] (p. 182). But one should be cognizant of making assumptions about individuals based on membership in a cultural group. HCPs should not essentialize Muslim people, but rather view them as having diverse needs, language, education, traditions, beliefs, practices, and social contexts. A "one size fits all" approach to healthcare practices will not work, thus individualizing healthcare is necessary. Noteworthy, "No individual is a stereotype of one's culture" ${ }^{[3]}$ (p 182). According to Hammoud, White and Fetters ${ }^{[19]}$ cultural knowledge can be divided into two categories, culture specific and general cultural knowledge. Culture specific knowledge corresponds with knowing a specific culture, while the latter has at its focus the general tenant of information regarding differences between cultures. Hammoud et al. ${ }^{[19]}$ assert cultural knowledge may enhance how one teaches or practices when embedded within a culture unlike their own. However, when HCPs have culturally specific knowledge they are better equipped to understand and support certain traditions when encountering patients. For example, "Muslim patients' modesty and privacy should be respected, and ideally, they should be cared for by a nurse of the same gender"[20] (p. 43). Many muslim patients also have "religious or Islamic practices rooted in the Qur' an"[21] (p.14). Muslim patients will interpret their illness as being Allah's will and if they are a good person their pain and suffering will elevate them in Jannah (heaven) or if they are a sinner their sins will be forgiven by way of their illness. ${ }^{\text {[2] }}$ Non-Muslim HCPs not aware of the Qur'an teachings may inadvertently disregard the patient's cultural beliefs and offer more pain medications. It is relevant to note that, although there is homogeneity in Muslim values, beliefs and practices, diversity also exists. For example, for many Muslims the teachings of Islam dominate every component of their values, behaviors beliefs. "But there are also acculturated Westernoriented Muslims - or 'cultural Muslims' - who may or may not adhere strictly to the practices of Islam"[23] (p.12).

This is also supported by a study conducted by AIYateem et al. ${ }^{[15]}$ who found that religion was a constant practice, exponentially more so when patients were ill or dying "more so than surgery or nursing procedures" (p. 23). However, findings indicated that HCPs who moved to the Middle East who did not have this concept embedded into their practice, lead to misunderstandings between the patient and the nurse. In essence, becoming aware of culturally specific knowledge affords one the opportunity to transition into the hospital setting in a way that embraces cultural specific domains of practice and prevents being culturally disrespectful to patients. Hence, HCPs must competently conduct cultural assessments with each of the patient's they provide care. Obtaining a cultural assessment allows both the nurse and client the opportunity to carry out a plan of care that takes into consideration the cultural background of the client. ${ }^{[24]}$ This also gives the nurse a sense of how culture is related to healthcare practice. The nurse must be sensitive when asking the client questions related to their illness narrative and have a sense of knowledge related to that particular culture.

\section{Cultural skill}

"Cultural skill involves collecting cultural data regarding a patient's history and completing a physical exam"[3] (p. 182). International HCPs might be able to conduct cultural assesments that encompasses a culturally based physical assessment especially with Muslim patients. Cultural assessment encompasses the cultural values, beliefs and practices of individuals, groups or communities necessary to meet the conextual needs and specific cultural interventions required. During a physical assessment of Muslim patients, HCPs need to be aware and respectful. ${ }^{[23]}$ of the values and practices of modesty, privacy, eye contact and proper use of touch. ${ }^{[19,23]}$ Also, according to Rassool, ${ }^{[23]}$ the extended family is consulted in many decisions regarding patient care. Thus, HCPs must be diligent in ensuring that healthcare decisions are family orientated. ${ }^{[25]}$ Further, Muslim patients ought to have physical assessments conducted by HCPs of the same gender as the patient, with permission granted prior to exposing the body. ${ }^{[23]}$ An example of this might be the act of touching a male patient's arm to acknowledge comfort or compassion. This type of gesture may not be welcomed as it goes against the cultural values and beliefs of gender difference. ${ }^{[19]}$ Further, modesty is also expressed by a female patient avoiding eye contact with a male HCP. This lack of eye contact should not be misconstrued as a lack of interest 
or lack of trust on behalf of the female patient. According to a number of authors ${ }^{[26,27]}$ a lack of cultural sensitvity on the part of the nurse leads to frustration and irritation as opposed to care carried out with cultural consideration on the part of the nurse.

\section{Cultural encounter}

"Cultural encounters implies direct contact and interaction with members of a cultual group and such encounters require awareness that experiences with a sampling of individuals cannot create expertise about a cultural group as a whole"[3] (p. 82). Interpretation of cultural encounters is predicated on the understanding that there will be wide variation within a cultural group and that faulty communication can occur when untrained interpreters intervene. Providing a learning environment that benefits students and offers them a safe haven whereby they can celebrate their cultural diversity is tantamount to an encounter that is productive as the students construct their own meaning of health. ${ }^{[28]}$ HCPs and educators alike need to be aware of the use of silence in Muslim culture, this may mean the use of introspection on the part of the patient or student and must not be taken as an awkward stance. Silence differs depending on the setting within one experiences it and "silence like spoken language serves many functions" "[29] (p.1).

Cultural encounter also invloves the use of an assessment of the linguistic abilities of the students one teaches. ${ }^{[3]}$ It is not uncommon when teaching a class of Muslim students to hear the low rumble of voices as you carry out your lesson plan. These students are translating to the ones in the class who are not as proficient in the English language. This could easily be misconstrued as inattentiveness or being disrespectful if not understood by the educator. Also, international educators and HCPs needed to be aware of the need to pray at intervals throughout the day for Muslim people. Thus, flexibility in delivery of care and education is warranted. Quappe and Canatore $^{[18]}$ suggest that cultural awareness exists at four levels, "My way is the only way, I know your way, but mine is better, My way and theirs and Our way (p. 2)." So how then will one react when all the students and patients families are wearing a hijab? In Canada we are full of open expressions, but what happens if it is not visible? How will you know you have students who are engaged in the topic at hand? What about the colloquial slangs used and the euphamisms non-Muslim HCPs and educators use? So how then do these translate to the broader culture of the Middle East and how will you assess this without knowing about the culture? These are questions that HCPs transitioning to the Middle East may want to ask themselves.

\section{Cultural desire}

Camphina-Bacote, ${ }^{[3]}$ refer to cultural desire as "the motivation of the health care provider to want to, rather than have to, engage in the process of becoming culturally aware, culturally knowledgeable, culturally skillful, and familiar with cultural encounters" (p.182). The concepts of caring, motivation, interest, genuine passion, willingness to learn are central to this construct. ${ }^{[3]}$ HCPs who have a desire to work internationally need to have the appetency to learn and immerse themselves into the culture which they chose to work. According to Duchscher ${ }^{[30]}$ it is inherent you know who you are in relation to where you will practice. Self-reflection, open-mindedness, compassion, flexibility and a genuine desire to learn are some of the essential ingredients needed to promote a successful transition when undertaking to live and work in the Middle East.

\section{Conclusion}

Whatever the motivation, choosing to live and work in another culture and context can present numerous challenges for HCPs who hope to make a successful transition and overcome culture shock. Internationally, HCPs intending to live and work in the ME are one expatriate group who regularly experience this kind of challenge. The use of a cultural model to guide cultural adaptation can help. The Camphina-Bacote process of cultural competence model is just one example guide which has been applied here to the context of HCP'S choosing to work in the ME. "This model of cultural competence in health care delivery is one model that HCP'S can use as a framework for developing and implementing culturally responsive health care services"[3] (p181). Although this model is seemingly intended to create a more responsive HCPs (better care for the receiver), it might help the provider with their individual/personal adaption by providing some of the insights needed to make a successful transition and assist with minimizing culture shock. Therefore, the model is beneficial to both the provider and to the receiver and it is that connection that culture shock may be ameliorated. This model provides a framework for developing knowledge of a culture. The ME presents a culturally rich learning opportunity for those willing and able to embrace the challenge. Campinha-Bacote's model can assist the international nurse to embrace that challenge and make a successful transition. The authors make some recommendations to assist HCPs in transitioning to work in the Middle East:

(1) Healthcare providers should be culturally aware by having a basic comprehensive of Muslim beliefs, values and practices to provide culturally safe and informed care

(2) Healthcare provider's must be culturally aware of their 
own beliefs both personally and professionally while unpacking any biases

(3) Time invested for the development of relationships with Middle Eastern clients, families and other healthcare professionals is essential

(4) Healthcare providers must have the cultural knowledge to individualize nursing care to meet healthcare needs within the unique context of culture, beliefs, values and practices.

(5) Healthcare provider's must attain cultural skills to be able to conduct cultural assesments that encompasses a culturally based physical assessment

(6) Healthcare provider's must have knowledge about cultural encounters in specific Muslim culture (ie. awareness of the use of silence)

(7) Healthcare provider's must engage in and learn about the particular Middle Eastern country and cultures prior to going overseas and immersing in the culture once they arrive.

\section{CONFLICTS OF INTEREST DISCLOSURE}

The authors declare that there is no conflict of interest.

\section{REFERENCES}

[1] Schumacher KL, Meleis AI. Transitions: A central concept in nursing. Journal of Nursing Scholarship. 1994; 26(2): 119-127. http: //dx.doi.org/10.1111/j.1547-5069.1994.tb00929.x

[2] Royal College of Nursing. Working with Humanitarian Organisations: A Guide for Healthcare provider, Midwives and Health Care Professionals. RCN, London. 2007.

[3] Campinha-Bacote J. The process of cultural competence in the delivery of healthcare services: A model of care. J Transcult Nurs. 2002; 13: 181-184. PMid:12113146 http://dx.doi.org/10.1177/1 0459602013003003

[4] World Health Organization, Global Health Workforce Alliance. Scaling Up, Saving Lives. Task Force for Scaling Up Education and Training for Health Workers, Global Health Workforce Alliance. WHO Geneva. 2008.

[5] Charles C, Daroszewski EB. Culturally Competent Nursing Care of the Muslim Patient. Issues in Mental Health Nursing. 2012; 33: 61-63. PMid:22224968 http://dx.doi.org/10.3109/0161284 0.2011 .596613

[6] Norton D, Marks-Maran D. Developing cultural sensitivity and awareness in nursing overseas, Journal of Nursing Standard. 2014; 28 : 39-44. PMid:24985303 http://dx . doi .org/10.7748/ns . 28.4 4.39. e8417

[7] El-Haddad M. Nursing in the United Arab Emirates: an historical background. International Nursing Review. 2006; 53(4): 284289. PMid:17083417 http://dx.doi.org/10.1111/j.1466-7 $657.2006 .00497 . x$

[8] Nehring V. A snapshot of nursing in Qatar. Nursing Education Perspectives. 2003; 24(5): 226-229. PMid:14535142

[9] Marhani AK, Yaghmaei F, Fard MK. Spirituality as experienced by Muslim oncology healthcare provider in Iran. British Journal of Nursing (Oncology Supplement). 2013; 22(4).

[10] Geertz C. The interpretation of cultures: selected essays. New York, NY: Basic Books. (Original work published 1973). 2000.

[11] Keighley T. Globalization, decision-making and taboo in nursing. International Nursing Review. 2011; 59: 181-186. PMid:22591088 http://dx.doi.org/10.1111/j.1466-7657.2011.00958.x

[12] Eschbach DM, Parker GE, Stoeberl PA. American repatriate employees' retrospective assessments of the effects of cross-cultural training on their adaptation to international assignments. International Journal of Human Resource Management. 2001; 12(2): 270-287. http://dx.doi.org/10.1080/09585190122882
[13] Xiu J. Analysis of Impact of Culture Shock on Individual Psychology. International Journal of Psychological Studies. 2009; 1(2): 97-101. http://dx.doi.org/10.5539/ijps.v1n2p97

[14] Briley D. The effects of culture on decision-making and judgment Research Frontiers: Newsletter of the Research Grants Council of Hong Kong China. 2007. Available from: http://www.ugc .edu . $\mathrm{hk} / \mathrm{rgc} / \mathrm{rgcnews} 13 /$ west/07.htm

[15] AIYateem S, AL-Yateem N. The Experience of Overseas Healthcare provider Caring for Muslim Patients in Kingdom of Saudi Arabia and UAE: A Qualitative Study. International Journal of Research in Nursing. 2014; 5(1): 17-26. http://dx.doi.org/10.3844/ijr nsp. 2014.17.26

[16] Papadopoulos I, Tilki M, Taylor G. Transcultural Care: A Guide for Health Care Professionals. Quay Books, Trowbridge. 1998.

[17] Canadian Healthcare Provider Association. (n.d.). Position Statement: Promoting Culturally Competent Care. Available from: http://cn a-aiic.ca/ /media/cna/page-content/pdfen/ps73_prom oting_culturally_competent_care_march_2004_e.pdf

[18] Quappe S, Cantatore G. What is Cultural Awareness, Anyway? How Do I Build It? 2011.

[19] Hammoud M, White M, Fetters CB. Opening cultural doors: Providing Culturally Sensitive Healthcare to Arab American and American Muslim patients. American Journal of Obstetrics and Genecology. 2006; 193(4): 1307-1311. PMid:16202719 http://dx.doi.org/1 $0.1016 / j . a j o g .2005 .06 .065$

[20] Padela AI, Rodriguez del Pozo P. Muslim patients and cross-gender interactions in medicine: an Islamic bioethical perspective. Journal of Medical Ethics. 2011; 37(1): 40-44. PMid:21041237 http: //dx.doi.org/10.1136/jme.2010.037614

[21] Rassool GH. Muslim and the Islamic faith: an introduction. In: Rassool GH (ed) Cultural Competence in Caring for Muslim Patients. Basingstoke: Palgrave Macmillan. 2014.

[22] Al-Furqaan Foundation is a registered 501(c)(3) non-profit da'wah organization based in Illinois, founded in 2003.

[23] Rassool GH. Cultural competence in nursing Muslim patients. Nursing Times. 2015; 111(14): 12-15. PMid:26182584

[24] Rankin SH, Stallings KD. Patient Education: Issues, Principles, Practices, 3rd ed. Philadelphia: Lippincott-Raven. 1996.

[25] Halligan P. Caring for patients of Islamic denomination: Cultural care healthcare provider experiences in Saudi Arabia. Journal of Clinical Nursing. 2006; 15(12): 1565-1573. PMid:17118079 http: //dx.doi.org/10.1111/j.1365-2702.2005.01525.x 
[26] Chenoweth L, Jeon Y, Burke C. Cultural competency and nursing care: An Australian perspective. Int. Council Nursing. 2006; 53: 34-40. PMid:16430758 http://dx.doi.org/10.1111/j.1 466-7657.2006.00441.x

[27] Jaber LA, Pinelli NR, Brown MB, et al. Feasibility of group lifestyle intervention for diabetes prevention in Arab Americans. Diabetes Res. Clin. Practice. 2011; 91: 307-315. PMid:21168232 http://dx.doi.org/10.1016/j.diabres.2010.11.032

[28] Aboriginal Healthcare Provider Association of Canada. Cultural Competence and Cultural Safety in Nursing Education. 2009. Avail- able from: http://cna-aiic.ca/ /media/cna/page-conte nt/pdf-en/first_nations_framework_e.pdf

[29] Green L. Breaking the code of silence to ensure quality care. Journal of Nursing Management. 2004; 210-305. http://dx.doi.org/10. 1097/00005110-200410001-00002

[30] Duchscher JB. A process of becoming: The stages of new nursing graduate professional role transition. The Journal of Continuing Education in Nursing. 2008; 39(10): 441-450. http://dx. doi .org/1 $0.3928 / 00220124-20081001-03$ 